This document is the accepted manuscript version of the following article:

Martin, H., Kerstin, Z., \& Joachim, M. (2019). Reduced emissions of warm mix asphalt

during construction. Road Materials and Pavement Design.

https://doi .org/10.1080/14680629.2019.1628426

\title{
Reduced emissions of warm mix asphalt during construction
}

\author{
Hugener Martin ${ }^{\mathrm{a}^{*}}$, Zeyer Kerstin ${ }^{\mathrm{b}}$, Mohn Joachim ${ }^{\mathrm{b}}$
}

\author{
${ }^{a}$ Laboratory for Road Engineering / Sealing Components, Empa - Materials Science and \\ Technology, Ueberlandstr.129, 8600 Duebendorf, Switzerland, martin.hugener@empa.ch \\ ${ }^{b}$ Laboratory for Air Pollution / Environmental Technology, Empa - Materials Science and \\ Technology, Ueberlandstr. 129, 8600 Duebendorf, Switzerland
}

Warm mix asphalt (WMA) is produced at lower temperature and hence its production in the asphalt plant is favourable in terms of energy consumption and $\mathrm{CO}_{2}$ emission. As a side effect, it is expected that the emissions during pavement construction are reduced too, which is highly relevant for work place hygiene and for environmental protection.

In a field trial five pavement sections were constructed with different warm-mix asphalt types and one hot mix asphalt (HMA) used as a reference. During construction several road workers were equipped with personnel samplers to determine their exposure to pollutants relevant for occupational health. Particular attention was paid to the total particulate matter (TPM) and the polycyclic aromatic hydrocarbons (PAH). In addition, emissions of TPM, PAH, and other organic pollutants (volatile organic compounds, TVOC) were sampled on paver and rolling compactor. To evaluate total emissions of road construction, an integrative pollutant sample was collected downwind of the construction site and mass emissions were estimated using a tracer gas technique with constant dosing at known source strength. In parallel a series of laboratory experiments were carried out on the same material to elucidate differences in the emission behaviour between the warm mix asphalt types and in relation to HMA under more controlled conditions.

The laboratory experiments indicate a $90 \%$ reduction of TPM and 50-70 \% lower TVOC values by the use of WMAs in comparison to hot mix asphalt. Emissions of pollutants during road construction, however, were low for all asphalt types, mostly below the occupational health limits and the detection limits of the applied analytical techniques. The study demonstrates the benefit of temperature reduction during road construction for occupational health and the environment.

Keywords: warm mix asphalt (WMA); emissions during construction; occupational health; PAH; TVOC 


\section{Introduction}

2 Reduction of energy consumption and $\mathrm{CO}_{2}$ emission is an important issue in asphalt produc-

3 tion. Hot mix asphalt (HMA) is still the actual standard in many countries although new tech-

4 nologies are available to produce asphalt at lower temperature (Kheradmand, Muniandy, Hua,

5 Yunus, \& Solouki,, 2014). Warm mix asphalt mixtures (WMA) are typically produced at

6 temperatures around 20 to $40^{\circ} \mathrm{C}$ lower than traditional hot mix asphalt. Different techniques to

7 produce warm mix asphalt are available, e.g. addition of waxes, chemical modifiers, zeolites,

8 foam bitumen, and it is difficult to evaluate the pros and cons of the different WMA types

9 (Rubio, Martínez, Baena, \& Moreno, 2012). Therefore, objective criteria are required to support decision-making by road authorities and other customers, including durability, ecological

11 balance and occupational health, for the right choice of WMA pavement type. construction as has been demonstrated in previous studies (Rubio, 2012; Hugener, Emmenegger, \& Mattrel, 2007; Autelitano, Bianchi, \& Giuliani, 2017). However, environmental agencies are cautious regarding WMA due to the lack of emission data. Furthermore, chemical additives of unknown composition are added to some WMA types, which could be released during road construction resulting in an occupational hazard for road workers (Rühl, Musanke, Kolmsee, Priess, \& Breuer, 2007). Moreover, warm mix techniques are often used in conjunction with recycled asphalt pavement material (RAP). RAP is sometimes heavily contaminated with tar, known to contain large amounts of toxic polycyclic aromatic hydrocarbons (PAH), which are released to some extent during construction. Measurements taken during actual road construction are required to determine the exposure relevant to occupational health, i.e. the harmful substances directly inhaled by the workers from mixtures and machines (paver, compactor, truck). Few emission measurements during road construction were conducted so far due to the complex sampling and analytical technique (Brandt, \& 
1 Cordingley, 1992; Hugener, Emmenegger, \& Mattrel, 2010; Kriech et. al., 2010) and even

2 less for WMA (Rubio, Moreno, Martínez, Martínez-Echevarría, \& Vázquez, 2013; Leon, \&

3 Jensen, 2012). One study on WMA with wax was restricted to the analysis of VOC emissions

4 from bitumen in a laboratory setup by headspace gas chromatography-mass spectrometry

5 (Autelitano et. al., 2017). More than 200 volatile compounds have been identified including

6 linear and branched hydrocarbons, cyclic alkanes, aromatic hydrocarbons and heterocyclic

7 (mainly sulphur) compounds. Another laboratory study on pollutant emissions of bitumen and

8 bituminous mixtures investigated the influence of different parameters (Gaudefroy, Viranai-

9 ken, Paranhos, Jullien, \& de La Roche, 2010).

In the paper presented here, emission and occupational health measurements were

11 conducted during sequential construction of four warm asphalt mixture types and one HMA

12 reference material in a field trial in Switzerland (Hugener et al., 2016).

\section{Materials and methods}

This study was part of the extensive research project PLANET (Arn, 2017) with different subprojects dealing with mix design, quality control, mixing plants, life cycle analysis, durability and occupational health. A central part of the project was a field test near Wohlen in the canton Bern (Switzerland), where on a rural road with a length of $850 \mathrm{~m}$ and a width of $6 \mathrm{~m}$, a binder course AC B 16 S (EN 13108-1, 2006) was constructed on October $6^{\text {th }} 2012$. Five different asphalt types, four WMAs and one HMA used as a reference (Table 1), were implemented sequentially in 5 equal sections of $170 \mathrm{~m}$ length. All mixes were identical in terms of binder content, penetration value and aggregate size distribution. Three different types of warm mix technologies were applied including foam bitumen, zeolite (WZ) and a chemical additive (WC) (Table 1). Two variations of foam asphalt were produced, one with $50 \%$ RAP (WFR) and one without recycling material (WF). 
2 was dry with temperatures ranging from $7.4^{\circ} \mathrm{C}$ in the morning to $23.6{ }^{\circ} \mathrm{C}$ in the late after-

3 noon. There were weak winds $(<0.1 \mathrm{~m} / \mathrm{s})$ from northeast in the morning, which turned to

4 southwest after the second section was finished. The road was constructed towards the north-

5 east with two asphalt pavers in parallel. First, a conventional hot mix asphalt was placed as a

6 reference with an asphalt temperature around $145^{\circ} \mathrm{C}$. Next, two warm-mix asphalts were laid

7 at temperatures between 120 and $130^{\circ} \mathrm{C}$. The first contained a surface-active chemical addi-

8 tive for reducing the friction in the mixture (WC), the second a hydrated zeolite (WZ), where

9 the adsorbed water formed temporary bituminous foam. Finally, the last two sections were

10 constructed using foamed asphalt (WF, WFR) at a temperature of $106^{\circ} \mathrm{C}$.

Table 1. Temperatures used for WMA and HMA production / construction

\begin{tabular}{l|ccc}
\hline Material & Warm mix technology & $\begin{array}{c}\text { Production } \\
\text { temperature }\left({ }^{\circ} \mathrm{C}\right)\end{array}$ & $\begin{array}{c}\text { Construction } \\
\text { temperature }\left({ }^{\circ} \mathrm{C}\right)\end{array}$ \\
\hline HMA (reference) & - & 165 & 145 \\
WC & Chemical additive & 135 & 123 \\
WZ & Zeolite & 135 & 128 \\
WF & Foam bitumen & 115 & 106 \\
WFR & Foam bitumen + 50\% RAP & 115 & 107 \\
\hline
\end{tabular}

\subsection{Emission measurements and sampling}

13 Six road workers with different tasks (2 paver drivers, 1 roller driver, 3 workers with univer-

14 sal tasks) were equipped with personal samplers to measure their occupational health expo-

15 sure. Stationary sampling devices were installed on two pavers with air sampling at roof

16 height of the pavers (Figure 1). An additional sampling was conducted at the lee side of the

17 construction site in order to determine the total emissions of the pavement activities. Dilution

18 of pollutants for the lee side measurements was considered using a tracer gas technique with

19 constant tracer gas dosing $\left(\mathrm{SF}_{6}\right.$ or $\left.\mathrm{SF}_{5} \mathrm{CF}_{3}\right)$ at the main emission sources (both paver and one

20 roller compacter) (Mohn et. al., 2018). Total emissions of a target substance were calculated 
1 as the ratio of target and tracer gas multiplied with the mass emissions of the tracer gas. A

2 combination of glass fibre filters and adsorption tubes filled with different resin types were

3 used to collect the pollutants at the three stationary measurement points and in the personal

4 sampler. Total particulate matter (TPM), total volatile organic compounds (TVOC) and the 16

5 EPA-PAHs (List of 16 PAH of the United States Environmental Protection Agency) were col-

6 lected on membrane filters and/or adsorption tubes (Supelco Orbo-43, Merck \& Co., US)

7 (Hugener et. al., 2010) with a flow of 2 l/min. TVOC were accumulated on thermal desorption

8 tubes (TDS-Tenax, Dräger Safety AG, Switzerland). Separate samples were collected for each

9 test section with a length of $170 \mathrm{~m}$, which limited the sampling interval to 40 minutes.

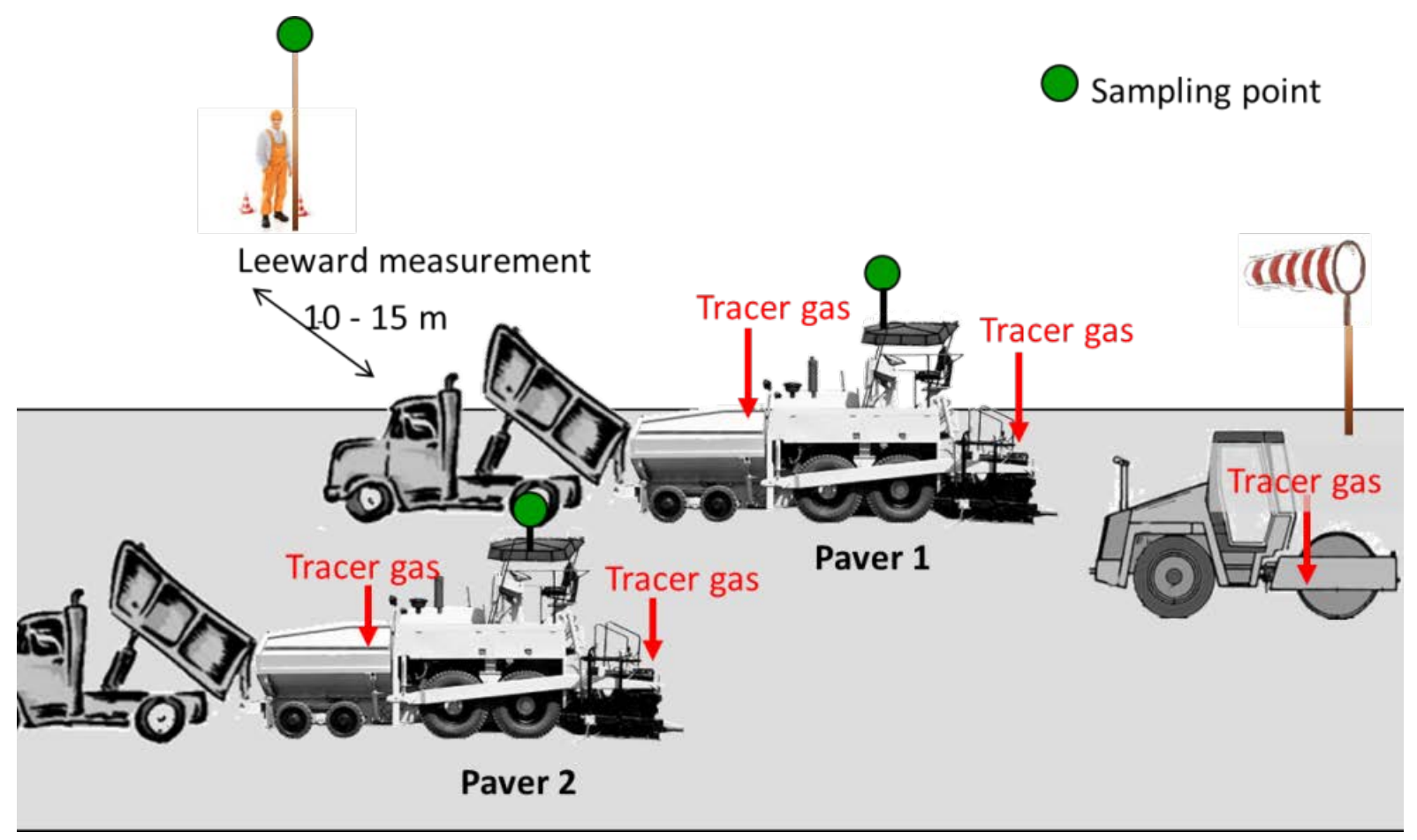

11 Figure 1. Schematic for tracer gas dosing and sampling points used during the emission measurements

13 Since the comparability of emission data for different WMA types based on field sampling is

14 limited even under defined construction conditions due to the differing topographical and me-

15 teorological conditions, results were complemented by laboratory measurements. This also

16 enabled a higher level of sensitivity for the analysis of pollutants, due to lower dilution ratios

17 and longer sampling intervals, as compared to the real construction site, where sampling in- 
1 tervals were limited due to the short test sections. For the lab measurements, four WMA and

2 one HMA subsample were collected at the construction site. In the laboratory the subsamples

3 were pre-heated first in closed containers over 3 hours to approx. $90^{\circ} \mathrm{C}$, in order to soften the

4 material, before the samples were transferred in a closed $150 \mathrm{~kg}$ laboratory mixer at construc-

5 tion temperature (Figure 2) and sampling was initiated. In this preheating phase some emis-

6 sions were lost, which, however also applies for the transport of the asphalt mixes from the

7 production plant to the construction site. Sampling for TPM, TVOC and EPA-PAHs was con-

8 ducted identically to the field measurements. In addition, the total organic carbon content was

9 measured continually with a flame ionization detector (FID) connected through a heated Tef-

11 carried out in the field trial as the device was not suitable for battery operation.

12

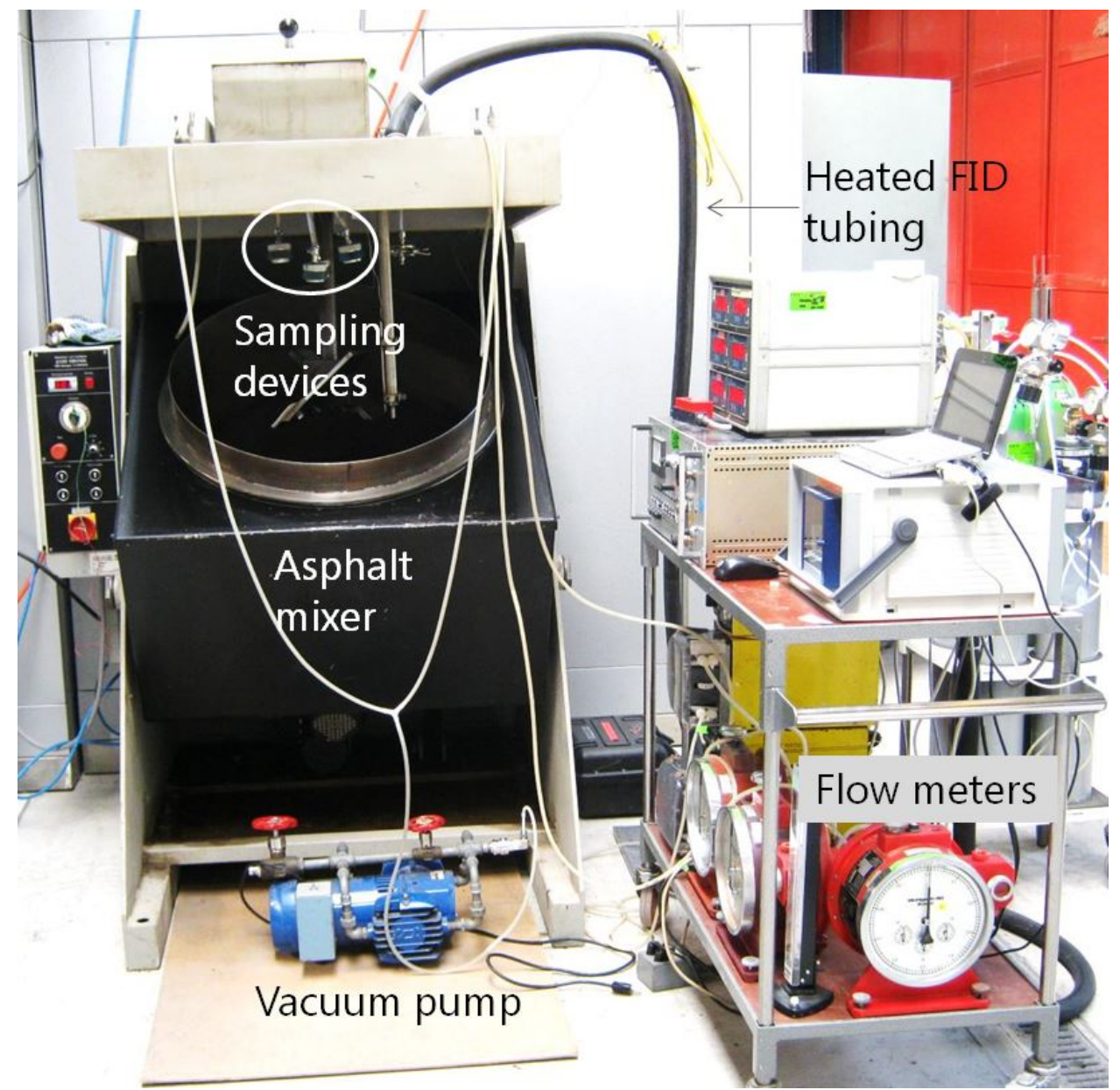

14 Figure 2. Laboratory measurements with $150 \mathrm{~kg}$ closed asphalt mixer 


\subsection{Chemical analysis}

2 Filters and adsorption tubes were extracted separately. Filters were extracted twice with $2 \mathrm{~mL}$

3 toluene in an ultrasonic bath. The solution was filtered and diluted to a volume of exactly 5 $\mathrm{mL}$ (Solution A). The resin of the PAH adsorption tubes was extracted twice with $2 \mathrm{~mL}$ of toluene within a 30 minute period with gentle shaking and diluted to $5 \mathrm{~mL}$ (Solution B). From one part of solution A the solvent was evaporated to determine the toluene soluble matter 7 (TSM).

To provide a representative sample for the analysis of the 16 EPA-PAH, $500 \mu \mathrm{l}$ of both solutions (A, B) were combined and an aliquote of $100 \mu \mathrm{l}$ was doped with an internal standard and analysed by GC-MS in multi-ion detection mode. TVOC analysis including sample preparation was performed according to ISO 16000-6 (2011). The substances enriched on the thermo-desorption tube were desorbed and after cryofocusing analysed by gas chromatography using a helium carrier gas and a mass selective detector with electron ionization (EI). Compound identification was performed by means of retention time and comparing the recorded mass spectra with a spectral library.

\section{Results and discussion}

In the beginning of the 2 hours laboratory experiments the material was heated to the construction temperature which was reached after 40 to 50 minutes (Figure 3). In the case of the reference HMA, a steep increase of the emissions (FID signal) is observed, which decreased in a similar way after the target temperature of $170^{\circ} \mathrm{C}$ has been reached (Figure 4). For the WMA this behaviour was significantly less pronounced, emissions stayed the same level for most of the time. Probably, the preheating phase was too long and depletion of the volatile compounds occurred already in the oven. 


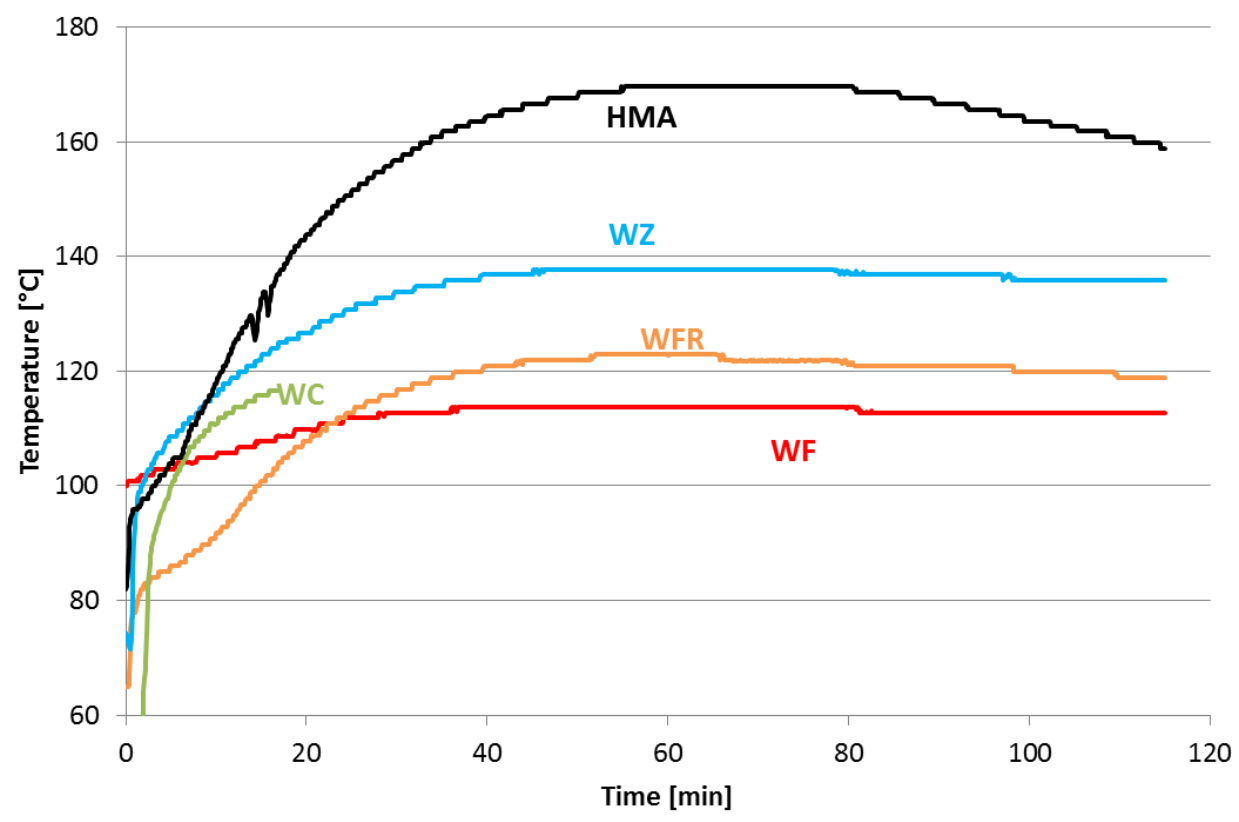

2

3 Figure 3. Temperature of the asphalt mixtures in the laboratory mixer. In the emission measurements 4 of material WC the data transmission was corrupted after 17 minutes causing erroneous data. 5

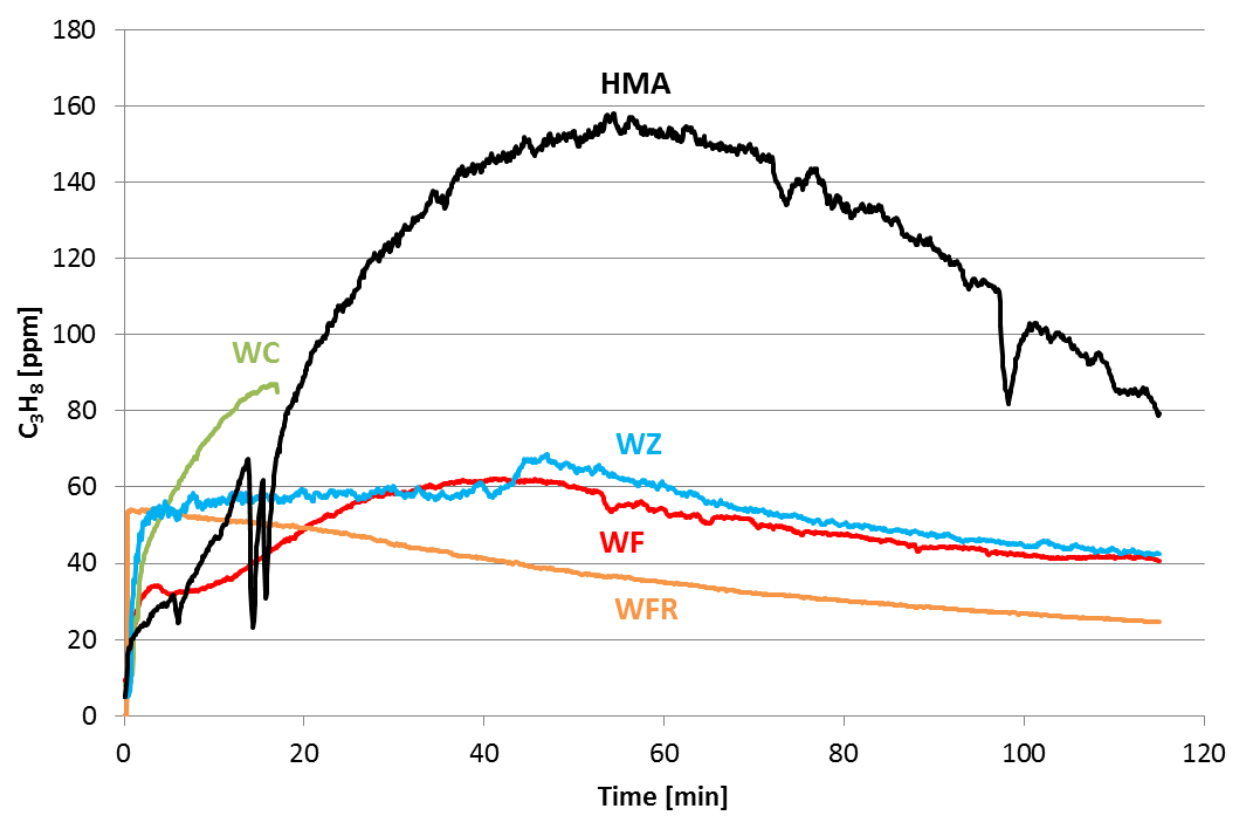

7 Figure 4. FID-signal representing the organic carbon emissions during the mixing procedure in the la8 boratory mixer. Short-term variations in the concentration were caused by temporary openings of the 9 mixer, which resulted in dilution with ambient air and therefore in a drop in the hydrocarbon concen10 tration. 


\subsection{Total particulate matter and total soluble matter}

2 The length of each test field of $170 \mathrm{~m}$, equivalent to 40 minutes of construction time, turned

3 out to be too short for the measurement of the low pollution concentrations. Consequently, not enough solid particles were collected on the filters for gravimetric analysis and most of the measured concentrations were below the detection limits. Total emissions for the roadbuilding were estimated based on target gas concentrations at the "leeward measurement site" and a dilution ratio determined from tracer gas concentrations and the volume of tracer gas

8 supplied.

In the field measurements, all TPM results, for all sampling locations (e.g. personal samplers) and all asphalt types, including HMA, were below detection limit and significantly below the Swiss regulated maximum workplace concentration (MAK) of $10 \mathrm{mg} / \mathrm{m}^{3}$ for bitumen fumes and aerosols (Suva, 2018). by the temperature of the mixture. Therefore, TPM emissions of HMA $\left(5.2 \mathrm{mg} / \mathrm{m}^{3}\right)$ were around ten times higher compared to warm mix asphalt, with TPM emissions close to the detection limits of $0.3 \mathrm{mg} / \mathrm{m}^{3}$. Between the different WMA technologies no clear difference in TPM and TSM emissions is visible. A better correlation was observed between the maximum asphalt mix temperatures and FID results. In the emission measurements of material WC the data transmission was corrupted after 17 minutes causing erroneous data. Hence, the maximum temperature and the total carbon amount (FID) in Table 2 were estimated from Figure 3 and 4 taking into account the data of the first 17 minutes. Assuming a similar evolution of temperature and FID signal like for the other mixtures, the maximum temperature was estimated to be between 120 and $130^{\circ} \mathrm{C}$. The average total carbon amount of WC is expected to 24 be higher than for WF but lower than for HMA. In contrast to findings of Gaudefroy et. al. 
1 (2010), we did not observe an increase in emissions due to water present in the foam bitumen,

2 which might be due to the low water content of around $1 \%$.

Table 2. Total carbon, TPM and TSM concentrations in the laboratory experiments

\begin{tabular}{lcccc}
\hline Material & $\begin{array}{c}\text { Maximum temperature } \\
\text { of the asphalt mix } \\
\left({ }^{\circ} \mathrm{C}\right)\end{array}$ & $\begin{array}{c}\text { Average of the total } \\
\text { carbon amount } \\
\text { (FID) }(\mathrm{ppm})\end{array}$ & $\begin{array}{c}\mathrm{TPM} \\
\left(\mathrm{mg} / \mathrm{m}^{3}\right)\end{array}$ & $\begin{array}{c}\mathrm{TSM} \\
\left(\mathrm{mg} / \mathrm{m}^{3}\right)\end{array}$ \\
\hline HMA & 164 & 124 & $5.2 \pm 3.9$ & $3.0 \pm 2.4$ \\
WC & $120-130^{*}$ & $60-90^{*}$ & - & - \\
WZ & 136 & 53 & $0.4 \pm 0.1$ & $0.3 \pm 0.1$ \\
WF & 113 & 34 & $<0.3$ & $0.2 \pm 0.2$ \\
WFR & 120 & 50 & $<0.3$ & $0.3 \pm 0.2$ \\
\hline *estimated values & & & &
\end{tabular}

3

estimated values

\section{$4 \quad$ 3.2. Total volatile organic compounds (TVOC)}

5 In the laboratory experiments, TVOC emissions for all WMA types displayed a similar emis-

6 sion profile with no emissions of additives or their derivatives being detected. As expected,

7 the proportion of higher boiling point hydrocarbons n-octane to n-eicosane within total TVOC

8 emissions was dominant, at $80 \%$ to $90 \%$. The concentrations of individual substances relevant

9 with respect to toxicity (e.g. benzene, toluene, cyclo-hexanone, benzaldehyde) were at least

10 two times lower than the prevailing MAK values. 


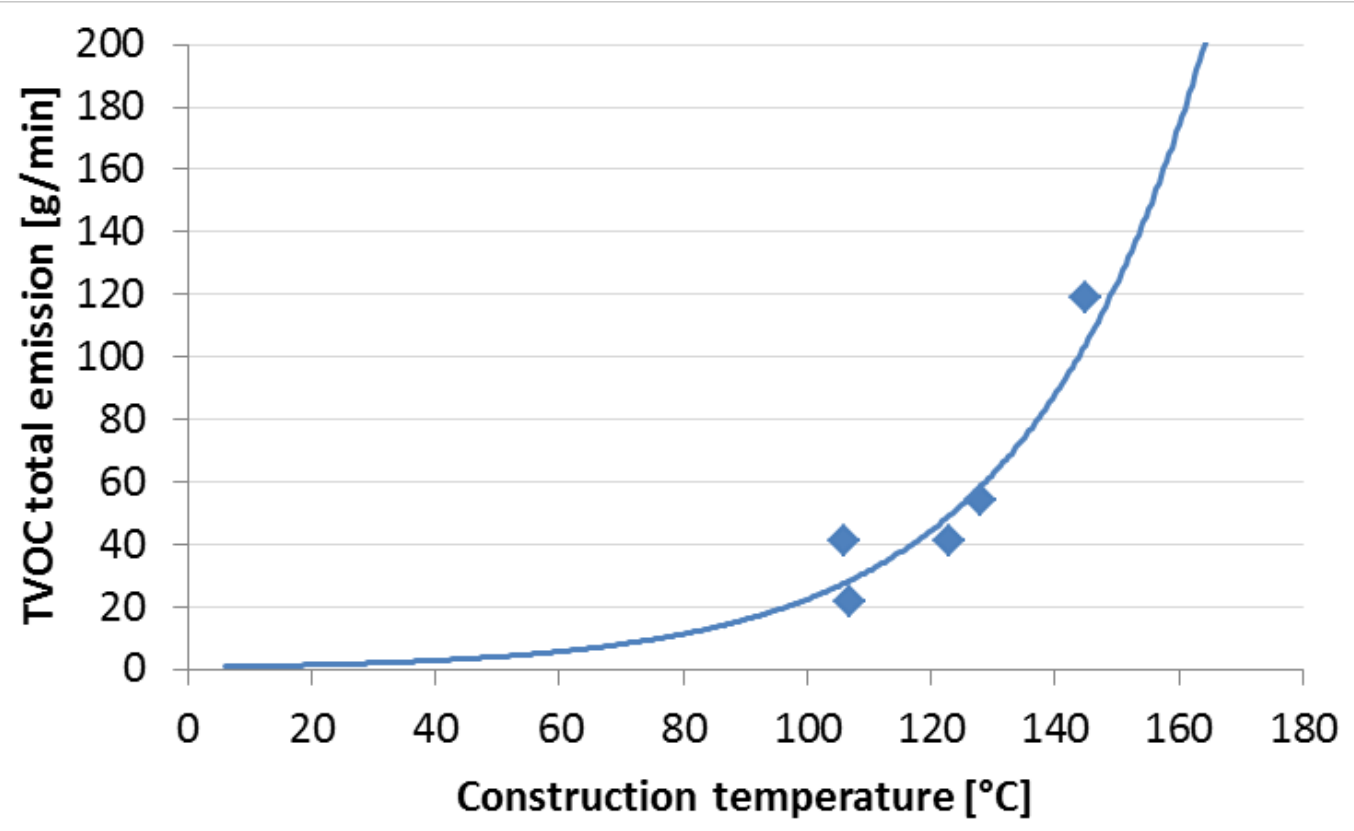

1 Figure 5. Correlation between TVOC total emissions and construction temperature determined in field experiments

3 In the field measurements no correlation between TVOC emissions and construction tempera-

4 ture was detected and concentrations were 100 to 1000 times lower than in the laboratory ex-

5 periments. This was attributed to differing meteorological conditions (e.g. wind speeds) re-

6 sponsible for varying dilution ratios and the fast depletion of these volatile compounds.

7 Accounting for target gas dilution using the tracer gas technique it was possible to calculate

8 total emissions of TVOC, which again showed a clear correlation with the construction tem-

9 perature (Figure 5). In the laboratory the TVOC concentrations were comparable for HMA,

10 WC and WZ, but 50\% lower for the two foam asphalt types (Table 3), which is in contrast to

11 the field results (total emission) and FID-measurements in the laboratory, where significantly

12 higher values for the HMA were recorded. 
Table 3. TVOC concentrations in laboratory and field experiments given in $\mu \mathrm{g} / \mathrm{m}^{3}$ and total emission in $\mathrm{g} / \mathrm{min}$

\begin{tabular}{lccccc}
\hline Material & Laboratory & Paver 1 & Paver 2 & $\begin{array}{c}\text { Leeward } \\
\text { measurement }\end{array}$ & Total emission \\
\hline HMA & 57800 & 700 & 39 & 3010 & 119 \\
WC & 57000 & 369 & 36 & 1380 & 54 \\
WZ & 47400 & 1050 & 386 & 837 & 41 \\
WF & 16800 & 1680 & 896 & 1570 & 41 \\
WFR & 23800 & 577 & 596 & 1340 & 22 \\
\hline
\end{tabular}

1

\subsection{Polycyclic aromatic hydrocarbons (PAH)}

The very low PAH release (Table 4) was apparently caused by a very low PAH content of the binders in the bituminous material. This was anticipated for the majority of the mixture types, since they do not contain any recycled material where tar could be present, which was used as a bitumen substitute in earlier time. Results were unexpected for WFR with 50\% RAP addition, showing only slightly increased PAH concentrations. Analysis of the applied RAP, however, revealed that it's PAH content of 25 ppm was rather low for Switzerland, where often PAH contents of 250 ppm and more are observed when tar is present. Similarly, benzo(a)pyrene, frequently used as a lead substance for toxicity, was below the detection limit.

In contrast to TPM and TVOC, and in contradiction to the literature (Hugener et. al., 2007; Gaudefroy et. al., 2010), PAH emissions did not show a temperature effect. This is attributed to the low PAH values which were always below or close to detection limits. For instance, PAH emissions were not elevated for HMA both in the laboratory and in the field campaign. Only the warm mix asphalt with 50\% RAP showed in general higher PAHconcentrations. Conclusions should be made with reservations, however, as all measured values were close to the detection limit. Such inconsistent results at very low PAH concentration levels were also observed by Rubio et. al. (2013) comparing emissions of HMA and halfwarm asphalt mixes. 
Table 4. $\mathrm{PAH}^{*}$ concentrations in $\mu \mathrm{g} / \mathrm{m}^{3}$ during construction and in the laboratory experiments

\begin{tabular}{lccccc}
\hline Material & Laboratory & Paver 1 & Paver 2 & $\begin{array}{c}\text { Lee- } \\
\text { measurement }\end{array}$ & $\begin{array}{c}\text { Personal sampler } \\
1-4\end{array}$ \\
\hline HMA & 13 & bdl & 36 & 31 & bdl -34 \\
WC & 12 & bdl & bdl & bdl & bdl \\
WZ & 14 & bdl & bdl & bdl & bdl -35 \\
WF & 11 & 53 & 34 & bdl & bdl \\
WFR & 22 & 49 & 46 & bdl & bdl -35 \\
\hline
\end{tabular}

1 bdl: below detection limits of $31 \mu \mathrm{g} / \mathrm{m}^{3} ; * 16$ PAH according the list of the US Environmental Protection Agency 2 EPA

\section{Conclusions}

5 In summary, it can be concluded that pollutant emissions during construction of warm-mix asphalt were low and below the valid MAK values (Suva, 2018), independent of the asphalt material, and often below the detection limits of the applied measurement techniques (TSM, TPM, PAH). This can be partly attributed to the short test fields and consequently short sam-

9 pling times and small sample gas volumes. In addition, laboratory experiments were conducted to normalize experimental conditions and increase sensitivity, resulting again in rather low emission values. For future research projects on diffuse emissions of warm mix-asphalt construction it would be beneficial to increase sensitivity of the applied sampling / analytical techniques. TVOC concentrations during construction in the field were equivalent to indoor

14 air, which is not surprising, since pollutant emissions were also low in the laboratory experi-

15 ments and outdoor emissions are significantly diluted with ambient air. Taking into account pollutant dilution using the tracer gas technique, TVOC emissions (total emission) during WMA construction were 2-5 times lower as compared to HMA. This was observed as well in the laboratory for the total carbon amount (FID signal). However, TVOC values of HMA and

19 the warm mix asphalt samples WC and WZ were similar. The low TVOC of HMA in the laboratory is in contrast to the other data and cannot be explained. 
2 close to the detection limit. Low emission levels can be rationalized by low PAH contents in

3 the asphalt mixtures, surprisingly also in the RAP, but the absence of a temperature correla-

4 tion is in contrast to results from earlier research projects on asphalt mixtures with higher

5 PAH contents (Hugener et. al., 2010). Results in the presented study might be impaired by in-

6 sufficient analytical sensitivity or loss of pollutants prior to experiments during preheating of

7 asphalt mixtures in the laboratory.

Nevertheless, the presented study demonstrates that reduction of construction temperature is an efficient measure to reduce pollutant emissions. TPM concentrations of warm mix asphalt are reduced by a factor of 10 and TVOC emissions are lower as compared to HMA. Concerning the different WMA types no significant difference was observed in terms of harmful emissions.

\section{Acknowledgements}

The research project was financed by the Federal Roads Office of Switzerland together with the Swiss Federal Laboratories for Materials Science and Technology Empa.

\section{References}

Arn, T. (2017), Forschungspaket PLANET: EP-0: Steuerung, Koordination und Synthese (Bericht Nr. 1619). Eidgenössisches Departement für Umwelt, Verkehr, Energie und Kommunikation UVEK, Bundesamt für Strassen.

Autelitano, F., Bianchi, F. \& Giuliani, F. (2017). Airborne Emissions of Asphalt/Wax Blends for Warm Mix Asphalt Production. Journal of Cleaner Production, 164, 749-756.

Brandt, H.C.A. \& Cordingley, N. (1992). Personal Exposures to Bitumen Fumes and PAC during Road Paving and in Laboratory Simulations. Proceedings of the 5th Eurasphalt Congress, The Hague, The Netherlands pp. 166-179.

EN 13108-1 (2006). Bituminous mixtures - Material specifications - Part 1: Asphalt Concrete. Brussels: CEN European Committee for Standardization. 
EN 12619 (2013) Stationary source emissions - Determination of the mass concentration of total gaseous organic carbon - Continuous flame ionisation detector method. Brussels: CEN European Committee for Standardization

Gaudefroy, V., Viranaiken, V., Paranhos, R., Jullien, A., \& de La Roche, C. (2010). Laboratory Assessment of Fumes Generated by Bituminous Mixtures and Bitumen. Road Materials and Pavement Design, 11(1), 83-100.

Hugener, M., Emmenegger, L. \& Mattrel, P. (2007). Zusammenhang zwischen PAK-Gehalt in teerhaltigem Recyclinggranulat und in den emittierten Dämpfen beim Wiedereinbau, Forschungsprojekt VSS 2000-453 (Bericht Nr. 1183). Eidgenössisches Departement für Umwelt, Verkehr, Energie und Kommunikation UVEK, Bundesamt für Strassen.

Hugener, M., Emmenegger, L. \& Mattrel, P. (2010). Hot-Recycling of Tar-Containing Asphalt Pavements. Emission Measurements in the Laboratory and in the Field. Road Materials and Pavement Design, 11(1), 29-46.

Hugener, M., Mohn, J., Zeyer, K., Seiler, C., Haag, R. \& Emmenegger, L. (2016). Forschungspaket PLANET - EP-7: Arbeitshygiene, (Bericht Nr. 1585), Eidgenössisches Departement für Umwelt, Verkehr, Energie und Kommunikation UVEK, Bundesamt für Strassen.

ISO 16000-6 (2011). Indoor air - Part 6: Determination of Volatile Organic Compounds in Indoor and Test Chamber Air by Active Sampling on Tenax TA ${ }^{\circledR}$ sorbent, Thermal Desorption and Gas Chromatography Using MS or MS-FID, Geneva: ISO International Organization for Standardization.

Kheradmand, B., Muniandy, R. Hua, L. T., Yunus, R. B. \& Solouki, A. (2014). An Overview of the Emerging Warm Mix Asphalt Technology. International Journal of Pavement Engineering, 15(1), 79-94.

Kriech, A.J., Emmel, C., Osborn, L. V., Breuer, D., Redman, A. P., Hoeber, D., Bochmann, F. \& Ruehl, R. (2010). Side-by-Side Comparison of Field Monitoring Methods for Hot Bitumen Emission Exposures: the German IFA Method 6305, U.S. NIOSH Method 5042, and the Total Organic Matter Method. Journal of Occupational and Environmental Hygiene, 7(12), 712-725.

Leon, J.G. \& Jensen P.H. (2012). Environmental Aspects of Warm Mix asphalts Produced with Chemical Additives. Proceedings of the $5^{\text {th }}$ Eurasphalt \& Eurobitume Congress, Istanbul, Turkey.

Mohn, J., Zeyer, K., Keck, M., Keller, M., Zähner, M., Poteko, J., Emmenegger, L. \& Schrade, S. (2018). A Dual Tracer Ratio Method for Comparative Emission Measurements in an Experimental Dairy Housing. Atmospheric Environment, 179, 12-22.

Rubio, M.C., Martínez, G., Baena, L. \& Moreno, F. (2012). Warm Mix Asphalt: An Overview. Journal of Cleaner Production, 24, 76-84. 
1 Rubio, M.C., Moreno, F., Martínez-Echevarría, M. J., Martínez, G. \& Vázquez, J. M. (2013). Comparative Analysis of Emissions from the Manufacture and Use of Hot and Half-Warm Mix Asphalt. Journal of Cleaner Production, 41, 1-6.

4 Rühl, R., Musanke, U., Kolmsee, K., Priess, R. \& Breuer, D. (2007). Bitumen Emissions on Workplaces in Germany. Journal of Occupational and Environmental Hygiene, 4, 77-86.

Suva - Schweizerische Unfallversicherungsanstalt (2018). Grenzwerte am Arbeitsplatz: Aktuelle MAKund BAT-Werte, Retrieved from: https://www.suva.ch/material/richtliniengesetzestexte/erlaeuterungen\%20zu\%20den\%20grenzwerten 